\title{
A AVALIAÇÃO ESCOLAR: INTENCIONALIDADE, FORMAS E INSTRUMENTOS
}

\author{
Renata Machado de Assis ${ }^{1}$ \\ Renata Gomes de Souza Fernandes ${ }^{2}$
}

\begin{abstract}
Based on the importance of considering school evaluation as an important tool in teaching practice, we had the interest in publishing this text, which is a fraction of a survey conducted in the year 2008. It is understood that school evaluation should be tailored for both the teacher and the student as a resource to assist in the teaching learning process. We understand that it is necessary a constant search for new researches and studies that address the assessment by teachers in all areas, and updating is vital for us to promote a fair evaluation according to the new developments of this issue at school, respecting the contextual specificities. It is necessary that the teacher seeks for theoretical and practical support to subsidize the assessment process, and there must be commitment to their initial training and continuous formation in order to provide spaces for reflection, discussion and professional growth.
\end{abstract}

Keywords: Evaluation; teaching practice; school.

Resumo: A partir da relevância de se considerar a avaliação escolar como uma ferramenta muito importante na prática docente, tivemos o interesse em publicar este texto, que se constitui uma fração da pesquisa realizada no ano de 2008. Entende-se que a avaliação escolar deva ser dimensionada, tanto para o professor como para o aluno, como um recurso auxiliar no processo de ensino aprendizagem. Compreendemos que se faz necessário uma constante busca de novas pesquisas e trabalhos que abordem a avaliação pelos professores de todas as áreas, e a atualização é primordial para que possamos promover uma avaliação justa e condizente com os novos avanços desta temática em âmbito escolar, respeitando as especificidades contextuais. É necessário que o docente busque respaldo teórico-prático para subsidiá-lo nos processos avaliativos, e que haja empenho em sua formação inicial e continuada, no sentido de propiciar espaços de reflexão, de discussão e de crescimento profissional.

Palavras-chave: Avaliação; prática docente; escola.

${ }^{1}$ Docente do curso de Educação Física (Licenciatura), do curso de Especialização em Educação Infantil e do Curso de Especialização em Avaliação e Prescrição de Exercícios Físicos para Populações Especiais do Campus Jataí/Universidade Federal de Goiás; Mestre em Educação pela UFMG; membro do NESEC - grupo de pesquisa do CNPQ. Contato: renatafef@hotmail.com

${ }^{2}$ Professora de Educação Física licenciada pelo Campus Jataí/Universidade Federal de Goiás; membro do NESEC - grupo de pesquisa do CNPQ. Contato: renatagsf@uol.com.br 


\section{Introdução}

Este estudo, aqui parcialmente publicado, surgiu a partir do fato de considerarmos a avaliação escolar uma importante ferramenta na prática profissional dos professores, uma vez que constatamos, em nossas experiências cotidianas, muitos equívocos no que se refere à utilização da mesma como verificação de resultados, ao invés de considerar o decorrer do ensino-aprendizagem. A avaliação deve ser utilizada como processo de compreensão dos avanços, limites e dificuldades dos estudantes para atingir as metas ou objetivos do curso, disciplina ou atividade da qual fazem parte.

A avaliação vem se estabelecendo com o status de verificação, conforme explicitado por Luckesi (2006), e não como avaliação da aprendizagem. Sendo assim, torna-se necessário discutir a avaliação e as formas de utilização deste instrumento no contexto escolar.

Por meio deste estudo, pretendemos entender um pouco mais sobre o tema em questão, e perscrutar os caminhos que devem ser tomados na busca de processos avaliativos coerentes para corresponder aos novos avanços no campo educacional, suscitando a reflexão, daqueles que devem compreender a importância deste recurso e tentar utilizá-lo de forma consciente em sua prática docente.

Com a elaboração deste artigo, buscamos, portanto, em uma abordagem preliminar, apresentar o que é a avaliação escolar e a sua importância como recurso didático, no processo de ensino aprendizagem de docentes e discentes, bem como a sua intencionalidade, as diferentes formas de avaliação, os conteúdos avaliados, os instrumentos adotados e a finalidade do ato avaliativo no sistema educacional de ensino.

\section{Avaliação escolar: Abordagem incial}

A avaliação educacional há muito vem sendo discutida por estudiosos contemporâneos, como Demo (1999; 2005), Luckesi (2006), Perrenoud (1999; 2002), Hoffmann (2000; 2005; 2006) e Vasconcelos (2005; 2006), dentre outros, que ao retratarem a necessidade de reformulações acerca da mesma, a fim de superar a abordagem positivista presente no cotidiano escolar, retomam o verdadeiro sentido ético da avaliação, ou seja, avaliar de forma coerente e justa o processo de aprendizagem dos alunos no ambiente escolar.

Entretanto, algumas questões nos remetem às reflexões sobre o desafio da escolha e utilização, de forma coerente, dos métodos avaliativos, que devem ser atribuídos em igualdade de condições e com os mesmos juízos de valores aos estudantes que possuem especificidades físicas, emocionais e cognitivas diferentes. $\mathrm{O}$ desafio seria como desenvolver, junto a esse aluno, o máximo de habilidades oferecidas no ambiente escolar, se o estudante também advém de meios diversos, recebendo e assumindo competências diferentes para se enquadrar neste sistema.

Verifica-se, portanto, que para procurar respostas às questões como essas citadas, devemos concordar com o fato de a avaliação ser ponto de pauta em quase todas as discussões pedagógicas na instituição escolar. Mas, o que acontece, muitas vezes, é o sistema escolar retomar a discussão e reflexão desse instrumento da didática, apenas quando aparecem seus resultados, como retratam Sacristán e Gómez (2000). Segundo esses autores, a constatação da importância da avaliação se manifesta quando a mesma se torna pública, o que a coloca como decisiva no processo de ensino.

Para Hoffmann (2005, p.29), a avaliação educacional deve orientar-se por valores morais e paradigmas científicos, ao lidar com a complexidade do ser humano. "Os processos avaliativos não podem ser fundamentados, apenas, em princípios, critérios e regras de investigação científica e considerações metodológicas...” (p. 29). 
De acordo com a autora, corremos o risco de não conseguir compreender o verdadeiro conceito da avaliação e sua relevante presença, para assim justificá-la como imprescindível no processo de ensino aprendizagem. Tomar consciência de sua ampla concepção e importância no desencadear da produção de conhecimento, propiciaria meios para assumir reflexões conscientes sobre os processos avaliativos, em todo o ambiente escolar. E para que tal realidade enfim aconteça, é preciso que todos os envolvidos neste contexto estejam empenhados e cientes dos seus papéis.

Analisar as práticas avaliativas poderá contribuir como forma de promoção da aprendizagem, englobando os novos preceitos da educação que devem, segundo Luckesi (2006), superar o autoritarismo e estabelecer a autonomia do educando, conforme o novo modelo social, que visa a participação de todos.

Para Demo (1999, p.25), “o efeito escolar da avaliação precisa ser meticulosamente colocado, para que se ganhe algum sentindo, não se restringindo a um mero incomodo ou repressão que possa atingir razões pedagógicas". O ato avaliativo na escola deve perseguir um sentido coerente para alcançar a meta, ou seja, a percepção concreta do que o aluno tenha realmente aprendido.

Esta percepção ficará explicita em uma nova discussão que retrataremos a seguir: a intencionalidade da avaliação, assim como a do próprio avaliador, que pode, direta ou indiretamente, vir a exercer influências, tanto positivas quanto negativas, no desencadear deste processo.

\section{A avaliação e sua intencionalidade}

$\mathrm{O}$ ato de avaliar está presente em todos os momentos da vida. Estamos sempre avaliando e a partir daí tomando decisões a partir de alguns poucos dados de que dispomos, como diz Kenski (1991). Podemos realizar também, às vezes, sem perceber, julgamentos provisórios e equivocados, o que nos leva a buscar sempre o melhor caminho a seguir, o que fazer, para onde ir ou mesmo sobre o que escolher.

Conforme Luckesi (2006, p.152), o ser humano age em função de algum resultado, seja econômico, material, político, amoroso ou até mesmo o simples prazer de viver o momento e, no sistema de ensino, em se tratando de avaliação, o aluno busca o melhor resultado: a aprovação. O conceito de avaliação é compreendido como atribuição de valor ou quantidade de alguma coisa. Tal fato nos leva à compreensão de que, para se avaliar deve-se ter que tomar, necessariamente, um posicionamento positivo ou negativo em relação ao que se avalia.

A avaliação sintetiza a maneira de se conceber o mundo, o aluno, a sociedade e o objeto a ser conhecido (conteúdos de disciplinas). Seu planejamento inclui estabelecimento de critérios e os procedimentos em que o professor se fundamenta para propor e realizar o seu processo de avaliação que, portanto, deve ser comprometido como parte integrante do processo educacional (SANTOS, 2005, p. 93).

Para isso, deve ser levado em conta um padrão de qualidade para compará-lo e atribuirlhe somatórios qualitativos de seu desempenho. Mesmo assim, características qualitativas podem se transformar em quantitativas durante este processo.

Segundo Luckesi (2006), a avaliação muitas vezes ganha status de verificação nas escolas brasileiras, já que o resultado da aprendizagem classifica, indiscutivelmente, o estudante. Este resultado se expressa na forma de aprovação ou reprovação.

O professor é uma figura imprescindível neste processo de investigação, pois ele é quem determina os processos avaliativos. Alessandrini (2002) diz que as competências básicas que 
cabem ao professor desenvolver devem estar ligadas à organização e à estimulação de situações de aprendizagem. "Para o professor desenvolver as competências na criança, ele precisa compreender e redescobrir as suas próprias competências. Precisa desenvolver a possibilidade de enxergar o outro [...] e de avaliá-lo, de observá-lo...” (p. 168).

Por meio desta citação, podemos observar que o professor é o principal sujeito deste processo e, como tal, cabe a ele o papel de realizar um processo avaliativo coerente no decorrer de suas aulas. Atualmente, não somente os professores, mas os pais e a própria instituição de ensino assumem a responsabilidade pelo sucesso ou não do aluno.

Aceitamos e lutamos por alguma coisa quando avaliamos positivamente, assim como rejeitamos outra, quando atribuímos a ela um valor negativo. $\mathrm{O}$ ser humano é um ser que avalia. Em todos os instantes de sua vida - dos mais simples aos mais complexos-, ele está tomando posição, manifestandose como não-neutro (LUCKESI, 2006, p.106).

Precisamos definir, primeiramente, qual é a intencionalidade de quem está na posição de avaliador. Vasconcelos (2005) comenta a intencionalidade, ou o para quê da avaliação, resumido-a em dois critérios: avaliar para classificar e excluir; e avaliar para intervir $e$ mudar.

A avaliação excludente é proveniente de um modelo autoritário de educação onde o professor é detentor de todo o conhecimento e incompatível a erros, e o aluno que não consegue aprender é o único responsável por isso. Sua dinâmica de trabalho gira em torno do aprovar e reprovar. Tal fato é comprovado no movimento histórico e econômico da sociedade até os dias atuais, em que nos deparamos com a ordem mundial excludente de uma sociedade capitalista altamente competitiva e seletiva.

Vasconcelos (2005, p.52) argumenta que esta avaliação “[...] ao invés de estar vinculada à vida (desejo, fluxo, movimento, empatia, engendramento, esperança), vincula-se à morte (fixação, rotulação, estigmatização, classificação, competição, impotência, dureza, frieza, distância, indiferença, descrença)".

Demo (1999) atribui à intencionalidade da avaliação a lógica classificatória, mas em um contexto mais amplo. Para ele, essa intencionalidade classificatória não gira somente em torno da remanescente disputa capitalista que se imputa aos indivíduos em convívio social, mas, também, em todo o contexto escolar, em um nítido confronto de classes.

Desse modo, o fundo classificatório de todo o processo avaliativo não aponta necessariamente para a relação capitalista de classes, mas sim para relação de clivagem social genérica e que no capitalismo comparece mais nitidamente no confronto de classes. Dizemos, pois, que ao avaliar é impossível apagar o plano de fundo da clivagem social em qualquer sociedade e que, na sociedade capitalista, esta clivagem tende sempre a se coagular de modo classista (DEMO, 1999, p. 15-6).

Perrenoud (1999) também retrata a avaliação a serviço da seleção ao afirmar que a mesma acaba criando na escola hierarquias de excelência onde, segundo ele, "os alunos são comparados e depois classificados em virtude de uma norma de excelência, definida no absoluto ou encarnada pelo professor e pelos melhores alunos (p. 11)." Além disto, antes mesmo de regular a aprendizagem, este tipo de avaliação também estabelece os parâmetros norteadores das relações de autoridade e cooperação em aula, das relações entre famílias e a escola, e dos próprios profissionais de educação. 
Tais concepções nos esclarecem a utilização deste meio de avaliação como promoção de poder e autonomia, esquecendo-se claramente da real finalidade da promoção do ato avaliativo: diagnosticar a aprendizagem do aluno.

Luckesi (2006) comenta sobre a avaliação excludente por meio do castigo para aquele aluno que não aprendeu determinado conhecimento ou uma sequiência metodológica. "A idéia da prática do castigo decorre da concepção de que as condutas de [...] um aluno que não correspondem a um determinado padrão preestabelecido, merecem ser castigadas, a firme de que ele 'pague' por seu erro e 'aprenda' a assumir uma conduta correta (p.52)." O aluno, ao não se enquadrar neste esquema, ou seja, ao não conseguir notas suficientes que o promovam, acaba sendo excluído pelo sistema, fazendo com que ele se sinta culpado de não tê-lo feito e punindo-o de forma criteriosa ${ }^{3}$.

Por outro lado, no que se refere à avaliação para intervir e mudar, citamos Darido (2005, p. 126-127): "a avaliação deve mostrar-se útil para as partes envolvidas - professores, alunos e escola -, contribuindo para o autoconhecimento e para a análise das etapas já vencidas, no sentido de alcançar objetivos previamente traçados".

Vasconcelos (2005), porém, nos traz a constatação de que não há como garantir em termos absolutos, a incorporação desta nova intencionalidade de avaliar para intervir e mudar. Segundo ele, existe sempre a real necessidade de se buscar e exigir atenção, espírito crítico, reflexão, investigação, enfim, caminhos para se assegurar a aprendizagem efetiva dos alunos.

Para Luckesi (2006), devemos promover a avaliação com a intencionalidade de um ato amoroso pois, desta forma, a mesma irá se referir ao acolhimento da situação da forma como ela se apresenta, ou seja, na sua mais pura verdade. Assim, por acolher uma situação da forma que ela é, sem julgamentos, sendo realizada impreterivelmente de forma amorosa, esta avaliação teria a sua intencionalidade contrária à da avaliação excludente, que citamos anteriormente.

A avaliação a serviço da ação deve ter por objetivo não a verificação e o registro de dados do desempenho escolar, segundo Hoffmann (2000). Ela deve se basear em uma observação constante das manifestações da aprendizagem para que se promova ação educativa e que aperfeiçoem os percursos individuais do conhecimento. Perrenoud (1999), assim como Hoffmann (2000), assume esta concepção de intencionalidade, e ambos afirmam ser importante uma avaliação a serviço não apenas de mudanças, mas também da aprendizagem.

Baseando-nos neste princípio, acreditamos que a intencionalidade avaliativa deve estar imbuída no sentido mais amplo de mudanças significativas no contexto escolar, pois, diante de tudo o que foi exposto, compreendemos que a intencionalidade do avaliador infere, diretamente, no objeto a ser avaliado, podendo tornar este processo coerente ou não, à medida que estipulam os seus critérios e intenções avaliativas.

Além da verdadeira intenção do avaliador, torna-se relevante também compreender as diferentes formas avaliativas que poderão ser utilizadas por ele, no processo qualitativo de avaliação escolar.

\section{A avaliação e suas diferentes formas e conteúdos}

Os conteúdos e as formas de avaliação são duas dimensões importantíssimas a serem retratadas no presente estudo por serem responsáveis, diretamente, pela concretização do ato avaliativo realizado pelo docente. O conteúdo que discutiremos a seguir versa sobre que é

\footnotetext{
${ }^{3}$ Mesmo parecendo cruel e desumana, a avaliação classificatória e excludente pode estar sendo utilizada de forma sistemática em vários estabelecimentos de ensino, em todo o país.
} 
tomado como objeto de análise. Em contrapartida, a sua forma irá se referir a como esta avaliação ocorre na instituição de ensino.

Vasconcelos (2005) diz que na perspectiva dialética, as formas e os conteúdos avaliativos acabam se sobrepondo, reciprocamente, e assim são referenciados à intencionalidade do avaliador.

No entender deste autor, devemos considerar, para compreender conteúdos e formas de avaliação, que a aprendizagem pode ocorrer sobre diferentes aspectos da realidade (indivíduo, sala de aula, instituição de ensino, sistema de ensino ou na sociedade como um todo) e, dependendo do foco, manifestar-se por meio de várias modalidades, como a auto-avaliação e a avaliação do sistema educacional e social, que se articulam inseparavelmente.

Luckesi (2006) afirma que a aprendizagem do educando acontece de duas formas distintas: espontânea e informal; e intencional e sistemática. A aprendizagem espontânea e informal ocorre nas múltiplas situações de vivência no cotidiano. Aprendemos na convivência com outras pessoas e em espaços não ocupados pela intencionalidade, numa situação de ensino sistemático. $\mathrm{O}$ aluno a busca na escola, e o professor oferece essa condição de aprendizagem metodicamente. Assim, a aprendizagem intencional vai além da aprendizagem espontânea. Ela não depende de ocorrências ocasionais, fortuitas, mas sim de buscas e exercícios sistemáticos para que ocorra.

Cruz e Fontana (1997) compreendem que a aprendizagem acontece por um processo de assimilação e acomodação. A inteligência é a assimilação, por permitir ao indivíduo incorporar os dados da experiência, e a incorporação de novos dados acaba por produzir modificações no sistema cognitivo desta pessoa.

Diante disso, Hoffmann (2006) sugere que para se construir uma avaliação que possa privilegiar o aprender e conseqüentemente o processo em que o mesmo se estabelece, em detrimento do aprendizado gerado apenas como um produto, a partir de uma visão dialética de conhecimento, o processo avaliativo deverá seguir dois princípios básicos: o da provisoriedade e o da complementaridade.

a) O princípio da provisoriedade - toda análise de tarefa ou manifestações de aprendizagem dos alunos deve encaminhar as novas perguntas, apoios ou desafios do professor, assim como as respostas que os alunos constroem considerando-as como ponto de partida para novas e mais questões; e

b) O princípio da complementaridade - onde o acompanhamento do aluno deve ocorrer ao longo do tempo em que as atividades escolares múltiplas de modo a promover a sua separação em termos intelectuais e de relações afetivas (p. 33).

No entendimento desta autora, o aprender é multidimensional e, com isso, a avaliação também deve se portar da mesma forma. Partindo, portanto, do princípio de que o aluno não aprende na escola somente conhecimento e hábitos, valores e atitude, mas também estruturas de pensamento (físicas e emocionais) durante o processo em que nela está inserido, tentaremos compreender de que forma a avaliação pode ocorrer no ambiente escolar.

\subsection{Habilidades a serem avaliadas}

De acordo com Coll, Palácios e Marchesi (1995), o homem tem o desenvolvimento muito semelhante ao dos animais e pode sofrer, como eles, influências em seu desenvolvimento, provenientes de dois grupos de fatores: internos e externos.

Os fatores internos que mais influenciam no desenvolvimento humano são conhecidos como a hereditariedade e a maturação. A hereditariedade consiste na herança individual, que 
cada criança recebe de seus pais, quando é concebida. A maturação, em contrapartida, consiste na mudança do organismo de dentro para fora como o tamanho dos órgãos, a forma que assumem o conhecimento e o desenvolvimento de habilidades como andar, correr, etc.

Já os fatores externos constituem o ambiente social (incluem o grupo social em que a pessoa vive, sua família, a escola, sua classe social), a alimentação e a preservação da natureza. O ambiente social é colocado por Coll, Palácios e Marchesi (1995) em local de destaque, em se tratando de fatores externos, pois dependendo da família, da classe social, e do tipo de sociedade em que nasce, a criança poderá ou não ter uma alimentação satisfatória e uma atmosfera favorável ao seu desenvolvimento. A falta de alimentação, por sua vez, interfere, e muito, no pleno desenvolvimento físico-motor, intelectual e afetivo do indivíduo. Por fim, a preservação da natureza consiste na preservação de um ambiente ecologicamente saudável, já que o indivíduo depende da natureza para sobreviver.

Percebemos que o indivíduo está sempre suscetível a mudanças, sejam elas em planos internos ou externos do seu organismo. Cabe ressaltar que ao entrar em sala de aula, nos deparamos com alunos que apresentam inúmeras adversidades físicas, cognitivas e afetivas que, se analisarmos criticamente, podem assim se apresentar pelo fato de terem sofrido defasagens ou ausências dos fatores internos e externos que possibilitariam o seu desenvolvimento. Portanto, devemos ter cautela no processo de avaliação, pois as instituições de ensino, pais e professores tendem a usar modelos igualitários de avaliação, apesar da diversidade de etapas evolutivas em que se encontram esses alunos.

Devemos perseguir uma linha de avaliação que contemple este aluno e seu pleno desenvolvimento, analisando e refletindo sobre seu processo de aprendizagem, de acordo com três grandes dimensões: o desenvolvimento físico e motor; as conquistas emocionais e sociais; e por fim, os aspectos intelectuais que a criança conquista durante os seus dois primeiros anos de vida.

O desenvolvimento físico e motor, segundo Coll, Palácios e Marchesi (1995), acontece de forma diferenciada nos indivíduos. No fim do primeiro ano de vida, o bebê pode ou não estar cerca de setenta centímetros do chão; nos primeiros dois anos até a adolescência, são os períodos em que o indivíduo tem o crescimento físico mais acelerado; e, no final da adolescência, atinge o seu nível máximo de crescimento. Os sentidos também são avaliados nesta dimensão, assim como os comportamentos reflexos (reflexo de andar, apreensão), as habilidades motoras (movimentar-se, agarrar, pular) que também dependem da idade e maturação fisiológica do seu organismo, pois cada criança tem seu ritmo próprio de desenvolvimento motor.

O desenvolvimento emocional e social se constitui de experiências que as crianças terão nas relações estabelecidas com os seres humanos, durante os primeiros anos de sua vida. Segundo Coll, Palácios e Marchesi (1995), ao nascer, o comportamento emocional da criança é o de uma excitação difusa que se manifesta sempre em mudanças bruscas de ambiente; mais tarde surge o desprazer ou aflição por volta do fim do primeiro mês; o prazer e a satisfação em torno do terceiro mês; no quarto e quinto mês a cólera, repugnância e medo; de nove a doze meses a animação e a afeição por adultos; com um ano e três meses, a afeição por crianças; um ano e quatro meses o ciúme e; por fim, com um ano e dez meses a alegria e as grandes risadas. Todo este processo ocorre devido ao processo de maturação afetiva, ou seja, processos internos que se manifestam de acordo com o desenvolvimento da criança.

O desenvolvimento intelectual ocorre principalmente nos dois primeiros anos de vida de forma surpreendente, desde o nascimento até a aquisição da linguagem. É neste período, considerado como sensório-motor, que a evolução intelectual passa por estágios importantes: estágio dos reflexos (de fundo hereditário); estágio da organização das percepções e hábitos 
motores; e, por fim, o estágio da inteligência sensório-motora (Piaget, citado por FURTADO e BOCK, 1999).

Mas, de acordo com Vasconcelos (2005), a avaliação realizada pelo discente pode ser divida em apenas duas dimensões de conhecimento, que seria a sócio-afetiva (ou atitudinal) e a cognitiva. A avaliação sócio-afetiva, segundo Vasconcelos (2006), compreende em avaliar as competências do aluno como atitudes, valores, interesse, esforço, participação, comportamento, relacionamento, criatividade, iniciativa e outros, mas sem vinculá-las à nota. Para realizá-la é necessário melhorar a formação de professores e a competência do avaliador (capacidade para observar, analisar, melhor conhecimento de psicologia) e suas condições de trabalho. Outros aspectos observados a serem avaliados, para além do desenvolvimento intelectual, são: o relacionamento com os colegas e professores; seu desenvolvimento afetivo; e a organização e hábitos pessoais.

A avaliação cognitiva, para Vasconcelos (2005), consiste no território clássico da avaliação escolar onde é comum a fragmentação do saber, a solicitação da devolução de informações, sem ocorrer o estabelecimento de relações entre as informações fornecidas. Em síntese, o professor quer ouvir do aluno exatamente o que ele transmitiu, para assim conseguir uma avaliação positiva do seu trabalho.

Contudo, para Darido (2005), a avaliação deve abranger não duas, mas três dimensões ou conteúdos a serem avaliados: cognitiva, atitudinal e motora. No aspecto cognitivo são avaliados as competências e conhecimentos dos educandos; no atitudinal (valores) a capacidade do aluno em expressar sua sistematização dos conhecimentos relativos à sua cultura corporal em diferentes linguagens corporal, escrita e falada; e, por fim, no motor são verificadas as habilidades motoras e capacidades físicas destes alunos.

Evidenciamos, neste momento, a nossa curiosidade a respeito do aspecto motor que, até então, ainda não tinha sido citado por nenhum dos autores em nossa linha de investigação, embora eles defendam insistentemente a construção de uma avaliação global dos alunos nos sistemas de ensino. Entendemos que Darido (2005) é uma autora da área de Educação Física, e que desta forma o aspecto motor se justifica, em suas colocações. Mas chamamos a atenção para o fato de que o aluno que freqüenta a escola, para cursar diferentes disciplinas, não matricula apenas o intelecto, mas o corpo inteiro. Todas as disciplinas ministradas no contexto escolar utilizam o corpo, em diferentes momentos e com finalidades diversas, o que justifica a avaliação também deste elemento, que é parte da constituição e formação humana.

A mútua descoberta entre aluno e professor passa, necessariamente, por processos dialéticos e diversificados entre observador-observado, analisador-analisado e avaliadoravaliado. Para responder a essa necessidade de parâmetros dialéticos, ele deve se apropriar de competências científico-pedagógicas que lhe permitam se valorizar e também às suas condições de trabalho, na intenção de otimizar o potencial de aprendizagem de seus alunos.

\subsection{Formas de avaliação}

A forma de avaliar, segundo Vasconcelos (2005), diz respeito ao como, ou à maneira concreta como a avaliação se desencadeará no cotidiano das instituições de ensino. Envolvem diretamente os rituais, rotinas, o desdobramento de diretrizes e normas, ou melhor, as maneiras de fazer e de expressar os resultados da avaliação da aprendizagem.

Em nosso estudo, percebemos que estas formas de avaliar acabam por receber inúmeras nomenclaturas. Cada uma delas pode expressar um sentido ou um foco avaliativo com maior ênfase ou não, como podem deixar para trás características imprescindíveis de serem observadas no processo de verificação da aprendizagem. 
Algumas obras consultadas (Perrenoud, 1999; Luckesi, 2006; Hoffmann, 2000; 2005; 2006; e outros) abordam a avaliação em relação à aprendizagem do aluno. É perceptível a preocupação desses autores no que se refere às informações deturpadas ou equivocadas, geradas pela variedade de formas em que o avaliador pode se perder e, por conseguinte, esquecer ou deturpar o real e necessário objetivo da avaliação.

Perrenoud (1999) afirma que a avaliação é polivalente nos sistemas de ensino, no qual as mesmas informações servem para fins muito diferentes, como: gerir a progressão do programa; motivar os alunos; manter a ordem; informar os pais e a administração; certificar o conhecimento; e garantir a aprovação. Sua crítica está na coleta e uso dessas informações, sem nem ao menos processá-las, constituindo-se, mesmo assim, em uma avaliação.

Existem inúmeras confusões geradas acerca da própria concepção do significado da forma avaliativa e dos instrumentos que podem se utilizados. Vasconcelos (2005) cita como exemplo a avaliação processual:

Sob a denominação "avaliação processual" encontramos compreensões muito diferentes: desde confundir-se como dar prova todo o dia, fazer enorme "contabilidade" de pontinhos, "não avisar" o dia da prova, até atribuir nota pela "carinha", não poder dar nenhuma atividade "mimeografada", etc. (p.103).

É importante buscarmos, para melhor compreender estas concepções, as inúmeras formas avaliativas, na intenção de compreender suas acepções e significados. Começaremos com a avaliação processual, que acabamos de citar.

A avaliação processual refere-se à atenção e ocupação permanente do professor com a apropriação efetiva do conhecimento por parte do aluno, com a interação aluno-objeto e conhecimento-realidade. Trata-se, portanto, de uma postura, um compromisso durante todo o processo de ensino-aprendizagem. No uso deste tipo de avaliação caberia a simples observação e conhecimento do aluno e não um elevado número de instrumentos para avaliálo. O professor e o aluno precisariam ter elementos objetivos e explícitos para julgarem o processo e o desenvolvimento. Os professores avaliariam com base na produção cotidiana deste mesmo aluno e não em atividades que tornam a avaliação artificial, fragmentada apenas aos momentos avaliativos.

No entender de Medeiros (1998), o termo se aplica a uma nova forma de avaliação, contínua, ao significado de um processo constante de avaliação, nos mais diversos momentos de um trabalho docente, onde ocorrem freqüentes verificações e qualificações dos resultados da aprendizagem para se detectar dificuldades e superar possíveis falhas decorrentes destas dificuldades, bem como para servirem de estímulo para o crescimento e promoção do aluno.

A avaliação contínua, apresentada por Sacristán e Gómez (2000), em muito se assemelha à avaliação processual retratada por Vasconcelos (2005). No entender de Sacristán e Gómez (2000), o conceito de avaliação contínua surge como alternativa para substituição dos exames que abrangem grandes quantidades de conteúdos, após longos períodos de aprendizagem. A continuidade significa um fracionamento da exigência, o que permite aos alunos a facilidade da comprovação do que aprendem.

Em se tratando da intenção pedagógica, esta avaliação continuada deve ser discutida, pois trazer para a sala de aula a aplicação de técnicas de forma incessantemente tradicionais de avaliação, acaba por descaracterizá-la, já que estimula apenas o controle permanente por meio da avaliação e não atende ao objetivo do processo de ensino-aprendizagem de forma processual.

Perrenoud (1999) ressalta a mesma preocupação em relação à intencionalidade pedagógica da avaliação contínua. Por outro lado, afirma que, de uma forma geral, os 
professores se beneficiam desta forma de avaliação por apresentarem maior autonomia nos sistemas escolares. Ele compõe, administra, corrige a nota, etc, conforme as diferentes exigências entre as turmas e os estabelecimentos de ensino. Desta forma, os alunos não serão julgados em relação às mesmas normas e níveis de exigência, o que possibilita que a escola se organize, levando em conta a grande diversidade de concepções e de práticas promovidas por este professor.

Demo (1999) apresenta a avaliação qualitativa, e esclarece, primeiramente, a não dicotomia entre a quantidade e a qualidade. Para ele, se nós, enquanto educadores, tomarmos a aprendizagem com noções cumulativas, ou seja, mero domínio de conteúdo e memorização mecânica, a nota (resultado da avaliação) tende a indicar apenas tamanhos extensos. Mas, em contrapartida, se ligarmos estes conceitos do saber pensar (reflexão) às habilidades de argumentar e questionar, essa mesma nota será levada a um dos objetivos da avaliação qualitativa: o fenômeno reconstrutivo.

O que muitas vezes é freqüente no ambiente escolar é o reducionismo destes conceitos, onde resultados considerados centrais acabam por fugir da sua definição concreta alteradas pela subjetividade de quem o avalia. A qualidade não pode ser reduzida à quantidade, embora muitas vezes ela possa ser representada por meio de faces quantitativas. Tal fato remete a dicotomia entre qualidade e quantidade como sendo irreal, pois é sempre possível, com a devida cautela e consciência do reducionismo que possa vir a acontecer, fabricar indicadores quantitativos de qualidade.

Compreendemos que a avaliação qualitativa é trabalhada de forma equivocada em relação ao seu significado de intensidade, na qual apenas se redimensiona o conceito de nota ou até mesmo a extingue, ao invés de se trabalhar a nota com a devida consciência crítica, acompanhada de comentários e propostas para facilitar a aprendizagem.

Vasconcelos (2005) cita a avaliação formal, que é o tipo de avaliação normalmente de caráter excludente, voltada para a mera verificação e classificação. O caráter excludente ainda permanece, segundo este autor, com a verificação ou classificação, que depende intimamente de cada época, legislação, normas, regimentos, etc. Outro aspecto a ser considerado é o perigo eminente deste tipo de avaliação formal ser transformada em essencial.

O perigo neste tipo de avaliação, também citado por Perrenoud (1999), é o de retratar que a aprendizagem acontece dentro do contexto escolar de forma sincronizada a ponto de poder ser aplicado com êxito o mesmo tipo de testes, nas mesmas condições, proporcionando aos alunos o mesmo tipo de conhecimento. Assim os professores, na maior parte do tempo, avaliam desempenhos individuais a partir de conceitos ou questões fechadas e padronizadas.

Passamos, desta forma, a correr riscos: ao atribuirmos o formal como aspecto essencial provocamos uma distorção, ao usar elementos quantitativos para avaliar. Acabamos reduzindo a avaliação apenas a aspectos quantitativos. O ideal seria possuir tanto elementos qualitativos (atribuição de uma qualidade a um aluno, trabalho, escola) quanto quantitativos (intensidade da qualidade apreciada por meios de graus de uma escala) de avaliação.

Perrenoud (1999) apresenta a avaliação formativa, que se sustenta na idéia de que o professor precisa observar metodicamente seus alunos, para que assim os compreenda melhor e, desta forma, ajuste de maneira sistemática e individualizada suas intervenções pedagógicas às situações didáticas que se apresentam em sala de aula.

$\mathrm{O}$ autor sugere a bifurcação entre a avaliação formativa e a avaliação contínua, pois assim, o professor conseguirá obter maiores informações, extremamente confiáveis, a respeito do aluno, permitindo lidar de forma eficaz com as aprendizagens em sala de aula.

Verifica-se, portanto, que esta forma de avaliação está centrada, intimamente, na gestão da aprendizagem dos alunos. $\mathrm{O}$ professor deve promover uma regulação intencional com o 
objetivo de determinar o caminho já percorrido por cada um e aquele que ainda resta para percorrer, tendo como meta a intervenção para melhorar os processos de aprendizagem.

Luckesi (2006, p.81) comenta sobre a avaliação diagnóstica: “[...] a avaliação deverá ser assumida como um instrumento de compreensão do estágio de aprendizagem em que se encontra o aluno, tendo em vista tomar decisões suficientes e satisfatórias para que possa avançar no seu processo de aprendizagem."

No entender deste autor, para a avaliação diagnóstica acontecer de forma não ilusória, ela não poderá estar a serviço da proposta política que classifica e exclui, que se reduz à mera atribuição de notas e conceitos aos alunos, não apresentando verdadeiramente sua função de prever o melhor resultado possível. Ao adotarmos a avaliação diagnóstica como prática, a postura docente deverá ser crítica e reflexiva.

Sacristán e Gómez (2000) citam a avaliação holística ou globalizadora, que em muito se assemelha à diagnóstica proposta por Luckesi (2006).

A avaliação compreensiva e globalizadora exige uma mudança na ideologia seletiva dentro do sistema educativo e dos próprios docentes, uma revisão das necessidades de formação do professorado para se dispor de uma mentalidade mais diferenciada em seu pensamento sobre o que é importante no ensino e no desenvolvimento do currículo. Exige novas necessidades na organização escolar. Ao não existir estas condições pode se explicar a permanência de pautas de controle defendidas pela avaliação tradicional, procedimentos rígidos de constatar o rendimento educativo, ainda que se tenha difundido diretrizes novas sobre como avaliar (p.344).

Ambas as propostas avaliativas remetem a não cometer equívocos em se tratando do real significado de suas ações. Elas sugerem também o preparo de professores e sistemas escolares para promover mudanças e adequá-las ao contexto.

Por fim, Hoffmann (2006) aponta a avaliação mediadora, que apresenta três princípios essenciais:

-O princípio dialógico/interpretativo da avaliação: avaliar como um processo de enviar e receber mensagens entre educadores e educandos e no qual se abrem espaços de produção de múltiplos sentidos para esses sujeitos. A intenção é a de convergência de significados, de diálogo, de mútua confiança para a construção conjunta de conhecimentos.

- O princípio da reflexão retrospectiva: avaliar como um processo que se embasa em leituras positivas das manifestações de aprendizagem dos alunos, olhares férteis em indagações, buscando ver além de expectativas fixas e refutando-as inclusive: o que o aluno é, como sente e vive as situações, o que pensa, como aprende, com quem aprende? Uma leitura que intenciona, sobretudo, planejar os próximos passos, os desafios seguintes ajustados a cada aluno e aos grupos.

- O princípio da reflexão-na-ação: avaliar como um processo mediador que se constrói na pratica. O professor aprende a aprender sobre os alunos na dinâmica própria da aprendizagem, ajustando constantemente sua intervenção pedagógica a partir do diálogo que trava com eles, com outros professores, consigo próprio, refletindo criticamente sobre o processo em andamento e evoluindo em seu fazer pedagógico (p.24-5).

O foco principal desta forma de avaliação é a prática refletida, que subentende também outra forma de avaliação: a reflexiva. Ela tem a verdadeira intenção de colocar em dúvida parâmetros fixos de julgamento, refletindo seriamente o que observa e tomando decisões 
pedagógicas adequadas e diferenciadas a respeito de cada aluno, promovendo, desta forma, melhores oportunidades de desenvolvimento dos mesmos, através da reflexão crítica da ação pedagógica dos avaliadores.

Os princípios citados por Hoffmann (2006) caracterizam em seu foco principal este tipo de ação, promovendo desafios intelectuais permanentes e de relações afetivas equilibradas no processo de promover a aprendizagem.

Em síntese, no decorrer da explanação sobre as diferentes formas de avaliação percebemos que, em todas as leituras feitas, os autores ressaltam e ao mesmo tempo defendem linhas de avaliação que, apesar de nomenclaturas diferentes, quase se espelham em seu significado por apresentarem, de forma lógica, o mesmo objetivo: a promoção e a verificação da aprendizagem do aluno, de forma coerente.

Inúmeros instrumentos podem ser empregados para execução destas formas de avaliação retratadas anteriormente. Cabe, portanto, ao professor, no ato de avaliar, estar completamente ciente e integrado ao verdadeiro significado da forma de avaliação que adotará para, então, escolher os instrumentos cabíveis à prática de tal ação. Equívocos podem ocorrer ao empregálas, mas, de forma geral, o mais importante é que estamos sempre a caminho de mudanças.

\subsection{Instrumentos de avaliação}

Segundo Hoffmann (2006), os instrumentos de avaliação são registros de diferentes naturezas como tarefas, testes, trabalhos, anotações e produções dos alunos analisados pelos professores em seus diários de classe, registros de secretarias e demais elementos que tenham a finalidade de verificar a vida escolar dos estudantes. Para esta autora, os instrumentos por si só não bastam, eles apenas terão sentido para quem os interpreta. Existem inúmeros instrumentos de avaliação que podem ser utilizados pelos professores para promover a verificação da aprendizagem dos alunos.

Segundo Piletti (1995, p. 197),

[...] para a avaliação diagnóstica, por exemplo, podemos utilizar o pré-teste, o teste diagnóstico, a ficha de observação ou qualquer outro instrumento elaborado pelo professor. Para a formativa, temos a observação, os exercícios, os questionários, as pesquisas, etc. E finalmente para a avaliação somativa, os dois tipos de instrumentos mais utilizados que são provas objetivas e as provas subjetivas.

Para entendermos melhor acerca dos instrumentos de avaliação, utilizaremos inicialmente as reflexões de Luckesi (2006), que enfoca a importância destes instrumentos na efetivação das formas de avaliação citadas anteriormente. Segundo o autor, os instrumentos de avaliação deveriam ser elaborados, executados e aplicados levando-se em conta alguns princípios, que devem: medir os resultados de aprendizagem claramente definidos, que deverão estar em devida harmonia com os objetivos instrucionais, com as amostras adequadas dos resultados e com o conteúdo da matéria incluída na instrução; conter os tipos de itens que são mais adequados para medir, bem como planejá-los para o ajuste ao uso dos seus participantes; e ser fidedignos para ser possível interpretá-los com cautela e utilizá-los na melhoria da aprendizagem do estudante.

Mas, para que estes princípios possam ser colocados em prática, percebemos que deve ocorrer clareza nos objetivos propostos destes instrumentos, para não ocorrer distorções em se tratando dos resultados gerados por eles. Os resultados deverão servir para diagnóstico da situação em que se encontra este aluno para que, desta forma, o professor possa intervir em 
sua prática pedagógica e promover ações no curso de sua docência, minimizando possíveis distúrbios ou falhas de aprendizagem.

Vasconcelos (2005) ainda ressalta que estes critérios devem estar à luz de uma pedagogia libertadora que deve considerar, para a elaboração dos instrumentos de avaliação, os critérios: essenciais, que dará ênfase aos conteúdos significativos; reflexivos, que através de situações complexas levem o aluno a pensar e estabelecer relações; abrangentes, em que a amostra significativa representará o que está sendo trabalhado; contextualizados, por permitir a construção do sentido do que está sendo pedido; claros, que devem dizer exatamente a que vieram ou mesmo o que querem; e por fim os compatíveis que, como o próprio nome diz, devem ser no mesmo nível ou grau de dificuldade aplicado no dia-a-dia do aluno.

Ao utilizar estes instrumentos deveríamos por em prática uma avaliação processual na qual o professor, estabelecendo um ambiente de confiança, deixa claras as regras do jogo, e explicita o que ele espera dos alunos em relação à avaliação realizada em vários momentos do processo de aprendizagem, com a devida e adequada previsão de tempo para possibilitar ao aluno a expressão do que verdadeiramente ele domina (VASCONCELOS, 2005).

$\mathrm{Na}$ análise destes instrumentos fica evidente, segundo Vasconcelos (2005), a falta de critérios claros, definidos e coerentes, tanto em termos de correção quanto em menções de valores. Sugestões trazidas por esse autor seriam: promover a análise (de macro para micro) do conjunto de todas essas atividades realizadas através dos instrumentos, para só então começar a se atribuir valores; ou mesmo, avaliar toda a turma para então passar para a análise da questão do desempenho individual de cada aluno.

De acordo com a síntese de como estes instrumentos deveriam ser construídos, empregados e analisados, passaremos então a identificá-los, de forma que visem à facilitação do processo de avaliação da aprendizagem. Iniciaremos com o mais tradicional e freqüente instrumento de avaliação, adotado durante anos e que perdura até os dias atuais, que é a verificação de conhecimentos por meio de provas e testes.

Segundo Piletti (1995), o objetivo das provas é o de verificação da quantidade de rendimento que o aluno apresenta. Ela pode ser do tipo objetiva (padronizada ou não) em que é dado ao aluno estímulo onde só existe uma resposta correta; e também do tipo subjetiva (padronizada ou não) que oferece a oportunidade de que o aluno opte por apresentar respostas corretas ou não, mas de acordo com o seu ponto de vista. Em relação à sua classificação, as provas objetivas são: as de escolher uma resposta (verdadeiro-falso, múltipla escolha, associação); as de evocação de uma resposta (completar lacunas, evocação, identificação); e as de ordenação de elementos (montagem e ordenação). Em relação às subjetivas, são classificadas como as de instrução para escrever, desenhar, esboçar respostas às perguntas, fazer dissertações, completar as frases ou estórias incompletas, resolver situações-problema, dentre outros.

Vários autores criticam este instrumento, como Vasconcelos $(2005 ; 2006)$, que afirma que a prova pode levar à ruptura do processo de ensino aprendizagem por dar demasiada importância à nota. Este instrumento acaba por se desvincular deste tipo de processo, pois seu objetivo final compreende apenas classificar o aluno, não contribuindo para um processo de repercussão em sua didática e reformulação pedagógica em sala de aula. O aluno estuda para aprender a tirar nota satisfatória para, ao final do ano letivo, ser classificado ou promovido para a série seguinte, valorizando, com este instrumento, apenas uma memória superficial que acaba, muitas vezes, sendo perdida pelo pavor e insegurança dos alunos para se conseguir a nota almejada.

Podemos perceber, a partir das argumentações desse autor, que este instrumento pode, muitas vezes, perder o foco de sua forma e objetivo avaliativo, uma vez que o aluno não deve estudar apenas para realizar uma prova. Ele deve, sim, construir e reconstruir conhecimentos, 
expressando opiniões e contextualizado idéias a partir do conteúdo apresentado para ele durante o ano letivo, afirmando ter conquistado sua autonomia e verificando, através de ações em seu cotidiano, o poder de reproduzir, sozinho, os conhecimentos apreendidos.

Outro instrumento que se assemelha muito às provas é o teste de medição de conhecimento. Apresentando as mesmas características e significado das provas, apenas remete a uma divisão de valores ou peso do resultado final da nota. Muitos professores aplicam testes ao invés de provas com o intuito de não promover uma avaliação em grandes proporções, dividindo-as em testes, que tem o seu peso ou valor diminuído, o que promove, maiores chances aos alunos.

O teste, segundo Hoffmann (2000, p. 52), é entendido também "como um instrumento de constatações e mensuração e não de investigação". Segundo ela, o professor, ao utilizar este instrumento, também constatará resultados expressos em valores numéricos, o que contribui para uma avaliação extremamente classificatória, pois o que se espera do aluno é a verificação de um resultado expresso por número atribuído pelo professor, naquele instante avaliativo.

Vasconcelos (2006) ainda enumera diversos instrumentos que podem auxiliar o professor na hora de verificar até que ponto os alunos apreenderam os conhecimentos mediados por ele durante o ano letivo.

O trabalho é um instrumento que poderá ser compreendido e executado por meio de outros tipos de avaliação, como, por exemplo, o questionário (série ordenada de perguntas ou discussões, com a finalidade de se obter respostas contextualizas ou não a respeito de determinado assunto ou conteúdos), as pesquisas (investigação sobre determinada realidade a fim de que se possa promover a possibilidade de conhecimento e reflexão sobre a mesma) e outros.

O trabalho pode ser realizado individualmente ou até mesmo coletivamente pelos alunos, caracterizado desta forma como trabalho em grupo. Esse instrumento muitas vezes é utilizado, segundo este autor, para melhorar a nota dos alunos que não foram bem nas provas ou testes aplicados.

$\mathrm{Na}$ prática, muitas vezes acontece de o professor, ao invés de reconhecer que o instrumento utilizado por ele não foi bem elaborado, optar por adotar este instrumento para, numa tentativa muitas vezes frustrada, promover uma recuperação dos conteúdos que não tiveram boa avaliação nas provas e testes realizados pelo aluno.

Constata-se, desta forma, que o autor nos chama a atenção para o fato de que o objetivo deste recurso também se foca na nota e não em um trabalho bem realizado para se conseguir obter conhecimentos significativos (ou o ato de aprender).

Este instrumento deveria ser uma tentativa de complementação ou de suporte, para auxiliar professores e alunos a alcançarem os objetivos estipulados ao longo do processo de aprendizagem. Assim ele conferiria ao aluno melhores formas de se apreender e, aos professores, formas de diagnosticar sua ação didática para promover, desta forma, intervenções pedagógicas.

Em síntese, os trabalhos propostos em sala de aula acabam se tornando um recurso para aumentar, quantitativamente ao invés de qualitativamente, o suposto conhecimento empírico que propõe os seus mediadores.

$\mathrm{O}$ instrumento participação consiste na avaliação dos alunos que acompanham freqüentemente as aulas durante o ano letivo. Na visão de Perrenoud (1999), a participação seria compreendida através dos atributos do ofício do aluno, ou seja, segundo ele, capacidades que desde o primeiro ano da escola o aluno deve aprender, tais como apresentar trabalhos e cumprir tarefas propostas (linhas e margens nos cadernos, colocar títulos, apresentar textos, fazer comentários, dar exemplos, perguntar), ou seja, o aluno sabe quando explicar uma 
resposta, quando colocar cálculos na margem, no verso ou em outra folha, quando consultar o dicionário, como apagar um erro, “[...] sabe quantas linhas deve escrever para fazer um texto decente, sabre que imprecisão pode se permitir quando constrói uma figura, faz uma medida experimental ou traduz um texto (p. 45)." Através dessas competências estariam explícitas habilidades indispensáveis a qualquer trabalho intelectual. Mas, muitas outras medidas são impostas pela própria instituição que configura a efetiva participação destes alunos.

Notamos certa preocupação por parte de Perrenoud (1999) em se tratando das competências que o aluno deve apresentar, o que retrata conseqüentemente sua participação ou não no processo de aprendizagem, para ser promovido na instituição de ensino. Além das capacidades e habilidades cognitivas que devem ser apreendidas para a promoção deste aluno, o mesmo deve também estar atento àquelas subentendidas como tal, mas que somente delegam a responsabilidade de adequar-se a leis e regras estabelecidas pela instituição, tornando-o apto ou não a fazer parte dela. Além disso, o professor, para realizar a avaliação por meio deste instrumento, terá que ter em mente os objetivos que foram traçados além de, através da escrita, explicar como aconteceu o processo de aprendizagem desse aluno.

Outro instrumento de avaliação é o parecer descritivo. Vasconcelos (2005) retrata que este instrumento é realizado por meio de registros, de relatórios e de pareceres descritivos (geralmente anotados em fichas através das quais se mapeia o desenvolvimento também atitudinal desses alunos) em substituição à nota, como forma de expressar os resultados da avaliação, para ajudar o professor a repensar seu curso, bem como a sua própria relação com os alunos.

Muitas vezes este instrumento vem acompanhado da verificação da freqüência, onde o simples fato de estar em sala de aula confere mérito ao aluno nestes tipos de instrumentos. Souza e Vago (1997) ressaltam que, através deste controle da frequiência, o aluno será avaliado apenas por se fazer presente, o que é incoerente, pois, de acordo com a LDB - Lei de Diretrizes e Bases da Educação Nacional - através do parecer n. 05/97, a exigência é de comparecer a $75 \%$ do total de horas letivas, caso contrário, o aluno estará automaticamente reprovado, independentemente de notas que conquistou ou dos conhecimentos que adquiriu durante o ano letivo. Portanto, devemos refletir se ao adotar apenas a frequiência, ao invés de avaliar saberes conquistados no processo de ensino aprendizagem dos alunos, serão adotados valores justos de avaliação, já que apenas o fato de o aluno estar inserido e presente diariamente neste contexto educacional não garante que o mesmo tenha ou não aprendido os conhecimentos mediados pelo professor em suas aulas, além de que ele tem direito a faltar a $25 \%$ das aulas no decorrer do ano letivo, o que não pode ser objeto de penalização.

Por fim, trazemos a questão da auto avaliação. A auto avaliação, se praticada em contextos não autoritários onde a prática da crítica e da reflexão são soberanamente estabelecidas, pode se tornar um instrumento de grande valor para o professor.

Segundo Vasconcelos (2005), para que este tipo de avaliação tenha efeitos positivos na aprendizagem, não deve ser objeto de introjeção de valores e padrões dominantes no sujeito. Este instrumento deve representar uma oportunidade de críticas e reflexões tanto do aluno, onde o mesmo refletirá sobre suas ações enquanto estudante em sua busca por conhecimento, como do próprio professor, que na função de mediador do conhecimento, poderá observar, refletir e intervir caso necessário, em sua prática no processo de ensino e aprendizagem.

No decorrer das afirmações dos autores anteriormente citados, podemos compreender que existe uma imensa confusão em relação a construção, adoção, aplicação e análise dos instrumentos, assim com das formas de avaliação adotadas pelos professores no momento de avaliação das competências cognitivas e sócio-afetivas dos alunos.

Destacamos a importância de o professor buscar conhecimento para estipular instrumentos adequados ou compatíveis com a forma de avaliação escolhida, englobando 
todas as habilidades de seus alunos. Caso contrário, ele poderá promover uma avaliação injusta, não cumprindo com o real objetivo proposto pela avaliação escolar, que é diagnosticar se ocorreu ou não a aprendizagem.

Podemos afirmar que a escolha, ou o para quê desses instrumentos, formas e conteúdos da avaliação, pode ser a principal causa de tantos equívocos, já que esta opção, principalmente no momento de conferir o resultado da aprendizagem no contexto escolar, está submetida a uma rede de intencionalidade e influências sobre as quais trataremos a seguir. Cabe ao professor refletir sobre os reais objetivos que devem denotar suas formas e instrumentos de avaliação para que assim, realmente, possa verificar as competências apreendidas ou não, de acordo com os aspectos cognitivos e sócio afetivos dos seus alunos, durante esse processo.

\subsection{Finalidade do ato avaliativo}

O olhar avaliativo, segundo Hoffmann (2006, p.26-27), é complexo por natureza e ao mesmo tempo multifuncional.

Caracteriza-se, justamente, por interpretações de diferentes intensidades e matizes (qualidades), sobre as múltiplas dimensões do aprender de cada aluno (aprendizagem), que se realizam de concepções de educação, de sujeito, de sociedade também diferentes (avaliação). Desta forma, os "juízos" de cada avaliador são sempre complexos e subjetivos a medida que se originam dessa trama de conceitos multifuncionais.

Devido a esta multifuncionalidade, compreendemos que é de indiscutível necessidade esse olhar permanecer, indefinidamente, no campo das incertezas, pois para que o mesmo assuma um papel transformador, ele deverá se portar de forma investigativa, sempre buscando novas informações e conhecimentos. A posse desta consciência é a chave essencial para promover uma avaliação justa, pois, no cruzamento de dados multifuncionais, não se pode ter a certeza de nada, mas, ao mesmo tempo, pode-se apresentar um compromisso com a ética, conhecimento e formação do aluno respeitando sua dignidade.

Estabelecendo com consciência a finalidade do olhar avaliador, passaremos, portanto, à adequação das finalidades deste olhar. Luckesi (2006) propõe finalidades avaliativas ao professor, que deve:

- coletar, analisar e sintetizar, da forma mais objetiva possível, as manifestações das condutas - cognitivas, afetivas, psicomotoras - dos educandos, produzindo uma configuração do efetivamente aprendido;

- atribuir uma qualidade a essa configuração da aprendizagem a partir de uma padrão (nível de expectativa) preestabelecido e admitido como válido pela comunidade de educadores e especialistas dos conteúdos a serem trabalhados;

- a partir dessa qualificação, tomar uma decisão sobre as condutas docentes e discentes a serem seguidas [...] (p. 95).

Para se utilizar uma avaliação do processo de ensino aprendizagem justa, o avaliador deve estabelecer critérios dos padrões mínimos de conhecimento, sim, mas também padrões de habilidades e hábitos do educando. Acima de tudo, deve promover uma constante reflexão acerca dos processos educacionais nos quais estão inseridos.

Sacristán e Gómez (2000) não abordam a função da avaliação apenas em relação ao sujeito observado mas, também, ao professor, instituição escolar, família e o próprio sistema 
escolar. Segundo os autores, a finalidade avaliativa não está condicionada ao pedagógico, pois a própria avaliação não surge para o aluno como uma necessidade de conhecimentos e de processos educativos.

Vasconcelos (2006) também cita os papéis hierárquicos ou influências de poder no processo de ensino aprendizagem, de todos os envolvidos neste contexto, que são: o sistema exerce o controle como forma de inculcação ideológica, domesticação, seleção e discriminação social; a escola - para legitimar sua própria existência como afirmação de sua importância e através de controle do trabalho dos professores; o professor - que toma como disciplina ou coerção para que o aluno reproduza a ideologia dominante, expressas no saber que ele oferece; e os pais - como forma de pressão e controle sobre os filhos, têm a nota como a única forma de acompanhar o desenvolvimento escolar das crianças.

Portanto, estamos historicamente condicionados a avaliar pela nossa função social, que também retrata a realidade educacional do nosso país. No contexto escolar, o processo de avaliação deveria ser realizado com instrumentos neutros para não serem questionáveis. Mas o caráter multifuncional da educação acaba por trazer contradições e exigências muito difíceis de serem harmonizadas.

Vasconcelos (2006) retrata o papel político da avaliação em relação à sociedade. O problema, segundo ele, é o tratamento da avaliação como instrumento de discriminação e seleção social que assume, no contexto escolar, a tarefa de separar no sistema os alunos aptos dos inaptos, os capazes dos incapazes, legitimando assim, o sistema dominante. "A escola ajuda este processo de discriminação social que deve necessariamente haver na sociedade capitalista, já que pela sua lógica excludente, não é possível que todos cheguem lá” (p.36).

Compreendemos, desta forma, que existem raízes profundas em relação à problemática da avaliação escolar. A adoção de uma forma de avaliação justa e altruísta para verificação do processo de ensino e aprendizagem, deve transpor barreiras e quebrar tabus deixando de ser considerada um objeto de um sonho muito distante.

A verdadeira e principal função da avaliação deveria perseguir valores morais e éticos no processo de aquisição de conhecimentos, visando a promoção da aprendizagem e englobando os novos preceitos da educação que devem, segundo Luckesi (2006), superar o autoritarismo e estabelecer a autonomia do educando, conforme o novo modelo social, que visa a participação de todos.

Perdendo seu significado, a avaliação muitas vezes pode trazer grandes transtornos. Utilizada como meio para promover a submissão dos alunos à autoridade dos professores acaba sendo uma arma na mão das causas disciplinadoras, um forte argumento para que o aluno preste atenção, comporte-se ou tire boas notas.

Vasconcelos (2005) confirma a associação da verificação da aprendizagem ao controle, fiscalização e disciplina. Segundo ele, o professor acaba sendo direcionado pelo ato avaliativo e não pelo processo estabelecido, no qual "seu papel na avaliação fica muito mais para juiz distributivo (dar prêmio ou castigo) do que para pedagogo (humanizar, ajudar aprender)" ( p.51). Logo, em nenhum momento, a avaliação pode ser utilizada como um mero artifício para promoção de medo ou traumas.

Outro fator importante é a própria concepção do conceito avaliação, que muitas vezes, percebe-se distorcidos e enraizados a motivos históricos e sociais, além dos pedagógicos. Para verificar este fenômeno, deve-se tomar o estudo do cotidiano escolar como fundamental para se compreender a forma pela qual a escola desempenha o seu papel socializador (FAZENDA, 2004).

Segundo Vasconcelos (2006), a avaliação escolar aparenta uma falsa neutralidade e objetividade, sendo na verdade um instrumento para o sistema de ensino controlar as oportunidades educacionais e para dissimular as desigualdades sociais. Assim, cabe ao aluno 
se desenvolver até onde o sistema o permita fazê-lo. As metas educacionais imbuídas pela escola remetem a juízos de valores já determinados, para o nosso convívio em sociedade, onde acabamos reproduzindo tudo aquilo que nos é ensinado.

Os alunos verdadeiramente capazes são rapidamente desencorajados e os outros tipos de inteligências destruídas. A escola, por sua vez, pela forma que está estruturada, engendra o tipo de avaliação tradicional de que necessita para manter esta alienação, como confirma Paro (2003).

Constatamos então, a partir das idéias de Paro (2003) e Vasconcelos (2006), que o professor no ato avaliativo é influenciado por um processo social (que o remete a uma sociedade que retrata a competição, consumismo e atribuição de valores distorcidos), assim como por parte das instituições escolares. O professor é uma figura imprescindível neste processo, pois determina os processos avaliativos. Alessandrini (2002, p.168) diz que as competências básicas que cabem ao professor desenvolver devem estar ligadas a organização e a estimulação de situações de aprendizagem. O autor coloca o professor como o principal sujeito deste processo e, como tal, cabe também a ele o papel de realizar um processo avaliativo coerente no decorrer de suas aulas, e assim, permanecer utilizando-o durante todo o processo.

\section{ENFIM, ISTO É UM INÍCIO...}

Buscamos, por meio deste artigo, abordar a avaliação escolar e sua importância no processo de ensino aprendizagem, ressaltando a sua finalidade, as formas, os conteúdos e os instrumentos utilizados para avaliar. Mas isto é um início, para incitar à busca por novos caminhos e novos "pensares" sobre algo que faz parte do nosso dia a dia profissional.

Acreditamos que uma formação continuada dos docentes deva ocorrer cotidianamente, pois novas tendências e metodologias avaliativas invadem o contexto educacional, e o professor deve se inteirar para que não incorra em práticas arcaicas e injustas, por falta de informação.

Cabe a cada profissional superar suas dificuldades diárias e agir de forma reflexiva, mantendo-se acessível às novas mudanças no campo educacional, principalmente no que se refere às práticas avaliativas.

\section{Referências bibliográficas}

ALESSANDRINI, Cristina Dias. O desenvolvimento de competências e a participação pessoal na construção de um novo modelo educacional. In: PERRENOUD, Philippe; THURLER, Mônica Gather (Orgs.). As competências para ensinar no século XXI: a formação dos professores e o desafio da avaliação. Porto Alegre: Artmed, 2002. p. 168-175.

COLL, César; PALÁCIOS, Jesus; MARCHESI, Álvaro. Desenvolvimento psicológico e educação: psicologia evolutiva. Porto Alegre: Artes Médicas, 1995.

CRUZ, Nazaré; FONTANA, Roseli. Psicologia e trabalho pedagógico. São Paulo: Atual, 1997.

DARIDO, Suraya Cristina. A avaliação em Educação Física na escola. In: DARIDO, Suraya Cristina; RANGEL, Irene Conceição Andrade (Coord). Educação Física na escola: implicações para a prática pedagógica. Rio de Janeiro: Guanabara Koogan, 2005.p.122-136.

DEMO, Pedro. Avaliação qualitativa. Campinas, SP: Autores Associados, 2005. 
DEMO, Pedro. Mitologias da avaliação: como ignorar, em vez de enfrentar problemas. Campinas: Autores Associados, 1999.

FAZENDA, Ivani (Org). Métodos de pesquisa educacional. São Paulo: Cortez, 2004.

FURTADO, Odair; BOCK, Ana M. Bahia. Psicologias: uma introdução ao estudo de psicologia. São Paulo: Saraiva, 1999.

HOFFMANN, Jussara. Avaliação: mito \& desafio- uma perspectiva construtivista. Porto Alegre, RS: Mediação, 2000.

HOFFMANN, Jussara. Avaliar para promover: as setas do caminho. Porto Alegre, RS: Mediação, 2006.

HOFFMANN, Jussara. O jogo contrário em avaliação. Porto Alegre, RS: Mediação, 2005.

KENSKI, V. M. Avaliação da aprendizagem. In: VEIGA, Ilma. Passos Alencastro (Coord.) Repensando a Didática. Campinas: Papirus, cap 8, 1991.

LUCKESI, Cipriano C. Avaliação da aprendizagem escolar. São Paulo: Cortez, 2006.

MEDEIROS, Mara. Didática e prática de ensino da Educação física: para além de uma abordagem formal. Goiânia: UFG, 1998.

PARO, Vitor Henrique. Reprovação escolar: renúncia à educação. São Paulo: Xamã, 2003.

PERRENOUD, Philippe. Avaliação: da excelência à regulação das aprendizagens. Porto Alegre: Artes Médicas Sul, 1999.

PILETTI, Claudino. Didática Geral. São Paulo: Ática, 1995.

SACRISTÁN, J. Gimeno; GÓMEZ, A. I. Pérez. Compreender e transformar o ensino. Porto Alegre: Artmed, 2000.

SANTOS, João Francisco Severo. Avaliação do ensino em educação física: uma proposta emancipatória. Revista digital - Bueno Aires - ano 10, N. 90 nov. 2005. Disponível em www.efdeporte.com. Data de acesso: 01/07/2008.

SOUZA, Eustáquia Salvadora; VAGO, Tarcísio Mauro. A nova LDB: repercussões no ensino de Educação Física. Presença Pedagógica. Belo Horizonte, n.16, p. 19-29, 1997.

VASCONCELOS, Celso Santos. Avaliação da aprendizagem: práticas de mudança por uma práxis transformadora. São Paulo: Libertad, 2005.

VASCONCELOS, Celso Santos. Avaliação: concepções dialética-libertadora do processo de avaliação escolar. São Paulo: Libertad, 2006. 